\title{
Allergen Inactivation with Colloidal Silica
}

\author{
Seiichi Tobe ${ }^{1 *}$, Hiroshi Akimoto ${ }^{2}$, Hajime Shigematsu ${ }^{3}$, Toshiyuki Watanabe ${ }^{4}$, \\ Masazumi Kikukawa ${ }^{1}$ and Hiroshi Miyazawa ${ }^{5}$ \\ ${ }^{1}$ Fabric-care Research Laboratories, Research \& Development Headquarters, Lion Corporation (7-13-12 Hirai, Tokyo 132-0035, JAPAN) \\ ${ }^{2}$ Planning and Coordination Department, Research \& Development Headquarters, Lion Corporation (7-13-12 Hirai, Tokyo 132-0035, JAPAN) \\ ${ }^{3}$ Analytical Technology Research Center, Research \& Development Headquarters, Lion Corporation (7-13-12 Hirai, Tokyo 132-0035, JAPAN) \\ ${ }^{4}$ Research Laboratories, Ipposha Oil Industries (1516-1 Oda, Hyogo 675-1301, JAPAN) \\ ${ }^{5}$ Department of Medical Technology, Faculty of Health Science, Kyorin University (467-1 Miyashita, Tokyo 192-8508, JAPAN)
}

\begin{abstract}
We evaluated the allergen inactivating effect of colloidal silica by performing enzyme-liked immunosorbent assay (ELISA) whose wells were coated with $150 \mathrm{ng} / \mathrm{mL}$ of Japanese cedar pollen allergen (Cry j 1) or mite allergen (Der f 2). The allergens were almost $100 \%$ inactivated by $100 \mu \mathrm{g} / \mathrm{mL}$ of colloidal silica having a particle size $5 \mathrm{~nm}$, and the inactivating effect was increased by aluminum binding to the surface of the colloidal silica. The results show that colloidal silica is a promising material for allergen inactivation. Since colloidal silica forms an insoluble nondispersive solid when dried, it is expected that airborne allergens can be reduced by binding them to colloidal silica.
\end{abstract}

Key words: colloidal silica, allergen, inactivation, ELISA

\section{INTRODUCTION}

The number of patients which have symptoms of allergic rhinitis, bronchial asthma, and atopic dermatitis is increasing with allergens derived from mites, animal pets, pollens, and cockroaches. Therefore, the removal, avoidance, and the inactivation of allergens are important to the reducing the symptoms ${ }^{1-3)}$. Some environmental allergens are known to be inactivated by tannic acid ${ }^{4)}$, and although the exact mechanism of inactivation is unclear, tannic acid strongly binds proteins, for example, modification of leather in tanning or inactivation of snake toxins ${ }^{5,6)}$. We therefore hypothesized that other materials with these characteristics would bind and inactivate allergens.

Colloidal silica is known to bind proteins ${ }^{77}$. Colloidal silica has particle sizes ranging from a few $\mathrm{nm}$ to $100 \mathrm{~nm}^{8)}$, and it is commercially available not only in various sizes and shapes, but even in surface-modified versions with metals such as aluminum. Colloidal silica has physical properties that are completely different from those of conventional powdered silica. It gives clear-colorless liquid dispersing in water as a primary particle. When the water in the liquid is evaporated, a huge secondary particle of water-nondispersive solid is formed by binding particles each other. Colloidal silica is a very popular material that is used not only to grind electronic materials and to remove sediment during wine making, but as an additives to inks and papers ${ }^{9-12)}$.

The purpose of this study was determined whether colloidal silica has allergen-inactivating ability. We evaluated the ability of colloidal silica to inactivate Japanese cedar pollen allergen (Cry j 1) and mite allergen (Der f 2).

\section{EXPERIMENTAL}

\subsection{Reagents}

Colloidal silica was obtained from Nissan Chemical Industries Corporation, ADEKA Corporation, Clariant Corporation, Fuso Chemical Corporation, and Shokubai Chemical Corporation. Japanese cedar pollen antigen (Cry j $1)^{13,14)}$, Dermatophagoide farinae mite antigen (Der $\left.\mathrm{f} 2\right)^{155}$, horseradish peroxidase (HRPO)-conjugated anti-Cry $\mathrm{j} 1$ (mAb 053), and HRPO-conjugated Anti-Der f 2 (mAb 13A4) were obtained from Seikagaku Kogyo Corporation. Other reagents were purchased from commercial sources.

\subsection{Evaluation of protein binding force}

The protein binding force of colloidal silica was evaluated by modification of Okuda's method for tannic acid ${ }^{16)}$. Colloidal silica was dispersed to $0.25 \%$ in $0.25 \mathrm{M}$ phosphate

*Correspondence to: Seiichi Tobe, Fabric-care Research Laboratories, Research \& Development Headquarters, Lion Corporation , 7-1312 Hirai, Tokyo 132-0035, JAPAN

E-mail: seto@lion.co.jp

Accepted March 18, 2008 (received for review January 7, 2008)

Journal of Oleo Science ISSN 1345-8957 print / ISSN 1347-3352 online

http://www.jstage.jst.go.jp/browse/jos/ 
buffer ( $\mathrm{pH}$ 6.0) containing $0.1 \%$ hemoglobin and maintained at $25^{\circ} \mathrm{C}$ for $30 \mathrm{~min}$. The solution was centrifuged at 4,500 rpm for $5 \mathrm{~min}$, and the optical density (OD) of the supernatant was measured at $578 \mathrm{~nm}$ with a Hitachi U-310 spectrometer. The protein binding force of each sample was calculated as

$$
\frac{\text { Blank OD-Sample OD }}{\text { Blank OD }} \times 100
$$

\subsection{Evaluation of allergen inactivation}

Allergen inactivating effect of colloidal silica was evaluated by ELISA ${ }^{17}$. After dissolving $150 \mathrm{ng} / \mathrm{mL}$ of Der $\mathrm{f} 2$ or Cry $\mathrm{j} 1$ in $0.05 \%$ sodium carbonate-sodium bicarbonate $(\mathrm{pH}$ 9.6) containing $10 \mu \mathrm{g} / \mathrm{mL}$ bovine serum albumin, $0.1 \mathrm{~mL}$ of each sample was placed in each well of a microplate $(96$ wells, Maxisorp, NUNC Corporation), and the microplate was incubated at $4{ }^{\circ} \mathrm{C}$ overnight. The wells of the microplate were washed 3 times with $0.2 \mathrm{M}$ acetic acid solution adjusted to $\mathrm{pH} 6.4$ with sodium hydroxide $(0.2 \mathrm{M}$ acetic acid buffer). A $0.15 \mathrm{~mL}$ of colloidal silica dispersed in $0.2 \mathrm{M}$ acetic acid buffer ( $\mathrm{pH}$ 6.4) was placed in each well, and microplate was maintained at $25^{\circ} \mathrm{C}$ for $1 \mathrm{~h}$. After washing the wells 3 times with $0.2 \mathrm{M}$ acetic acid buffer ( $\mathrm{pH}$ 6.4), $0.1 \mathrm{~mL}$ of HRPO-conjugated anti-Der $\mathrm{f} 2$ or -Cry $\mathrm{j} 1$ diluted 1,000 fold with $0.2 \mathrm{M}$ acetic acid buffer ( $\mathrm{pH}$ 6.4) containing $1 \%$ BSA and $0.05 \%$ Tween 20 was added to each well, and the microplate was maintained at $37^{\circ} \mathrm{C}$ for $60 \mathrm{~min}$. The wells were then washed 3 times with $0.2 \mathrm{M}$ acetic acid buffer ( $\mathrm{pH}$ 6.4), and $0.1 \mathrm{~mL}$ of $0.037 \mathrm{M} o$-phenylenediamine dissolved in $0.051 \mathrm{M}$ phosphate, $0.027 \mathrm{M}$ citric acid buffer with $0.012 \%$ hydrogen peroxide ( $\mathrm{pH} 5.0$ ) was added to the each well and allowed to react at room temperature for 15 min. The reaction was stopped with $0.05 \mathrm{~mL}$ of $2 \mathrm{M}$ sulfuric acid. The OD of each solution was measured at $492 \mathrm{~nm}$, and the inactivation rate was calculated as

$$
\frac{[(\mathrm{A})-(\mathrm{B})]-[(\mathrm{C})-(\mathrm{D})]}{(\mathrm{A})-(\mathrm{B})} \times 100
$$

(A): OD of a colloidal-silica-free sample

(B): OD of a colloidal-silica-free and antibody-free sample

(C): OD of a sample containing colloidal silica

(D): OD of an antigen-free sample containing colloidal silica

\subsection{Analysis of inactivated allergen}

An aqueous solution of Der $\mathrm{f} 2$ was prepared by dialysis with a membrane (Slide-A-lyser Dialysis Vassette 10,000 MWCO, PIERCE Corporation) in $10 \mathrm{mM}$ acetic acid buffer $\left(\mathrm{pH}\right.$ 6.4) at $4^{\circ} \mathrm{C}$ for $2 \mathrm{~h} 3$ times and for 16h. In accordance with Kondo's method ${ }^{7}$, each $33 \mu \mathrm{g} / \mathrm{mL}$ solution of Der $\mathrm{f} 2$ in $10 \mathrm{mM}$ acetate buffer ( $\mathrm{pH}$ 6.4) with $1 \%$ or without colloidal silica, SNOWTEX XS, having a particle size of $5 \mathrm{~nm}$ was maintained at $25^{\circ} \mathrm{C}$ for $2 \mathrm{~h}$, and the samples was analyzed by circular dichroism (CD) spectrometry (J-720, JASCO Corporation).

\section{RESULTS AND DISCUSSION}

\subsection{Protein binding force of colloidal silica}

Although colloidal silica is known to have a protein binding action, the relationship between binding force and particle size had never been thoroughly investigated. We evaluated the rate of hemoglobin aggregation by colloidal silica as an indicator of its protein binding force. As shown in Fig. 1, the rate increased as particle size decreased, and the correlation coefficient between logarithm of particle size and percentage of aggregation was -0.950 . Colloidal silica with a particle size of $5 \mathrm{~nm}$ had a rate of approximately $80 \%$, equal to that of tannic acid, suggesting that colloidal silica with a small particle size has superior protein binding force. We would like to discuss the relation between the binding force and the particle size. As shown in Fig. 1, the binding force is inversely proportional to the logarithm of the particle size. The mechanism of this interaction is not clear, but by assuming the similarity to the interaction of tannic acid with protein, it can be thought that silanol groups on the colloidal silica surface must interact with protein by hydrogen bonding. Therefore, the degree of interaction depends solely on the surface area in case for a group of colloidal silica with the same surface nature. The change in surface area per mass (specific surface area) was

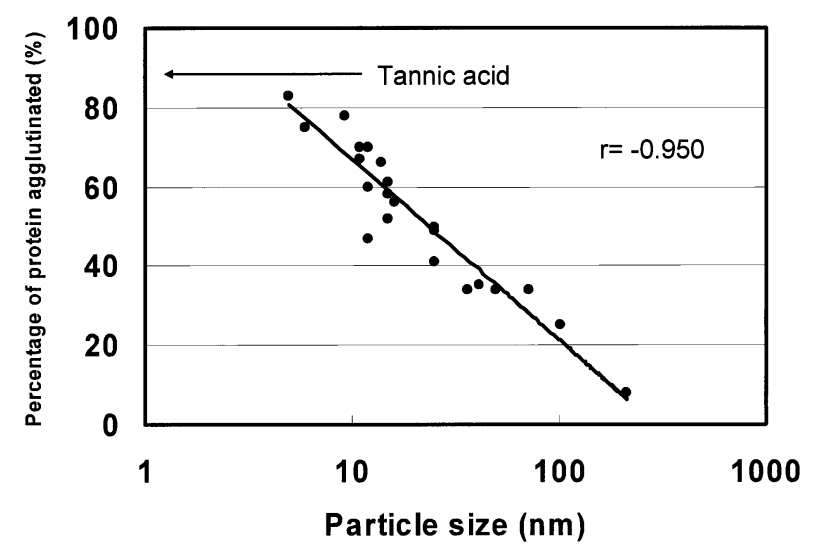

Fig. 1 Rate of Hemoglobin Aggregation by Colloidal Silica Having Different Particle Sizes.

A $0.1 \%$ hemoglobin solution in $0.15 \mathrm{M}$ phosphate buffer (pH 6.0) containing $0.25 \%$ of colloidal silica was maintained at $25^{\circ} \mathrm{C}$ for $30 \mathrm{~min}$. The rate was determined from the absorbance of the supernatant obtained by centrifugation. 
calculated for the silica with different particle sizes. Assuming smooth spherical particles (radius: $r$ ) for simplification, volume and surface area are $4 \pi \mathrm{r}^{3} / 3,4 \pi \mathrm{r}^{2}$, respectively. When the particle size is reduced to a half of the original at the same concentration, the total number of the particle will be eight times as much as the original size, because total volume is constant, that is, $4 \pi \mathrm{r}^{3} / 3=8 \times 4 \pi$ $(\mathrm{r} / 2)^{3} / 3$. The total surface area for the half size will be double to that for the original size, that is, $8 \times 4 \pi(\mathrm{r} / 2)^{2}=2 \times$ $4 \pi \mathrm{r}^{2}$. Now, one relation becomes clear that the product of particle size (2r) and total surface area (A) is constant. The rate of aggregation $(\mathrm{Y})$ is proportional to $\mathrm{A}$, if the aggregation will proceed regardless of the concentration of protein or silica. Then, the product of particle size and the rate of aggregation is also constant.

$\mathrm{rA}=\mathrm{K}_{1}(1)$

$\mathrm{Y}=\mathrm{K}_{2} \mathrm{~A}(2)$

$\mathrm{rY}=\mathrm{K}_{1} \mathrm{~K}_{2}(3)$

Then,

$\log \mathrm{y}=-\log \mathrm{r}+\mathrm{K}_{3}(4)$

$\left(\mathrm{K}_{1}, \mathrm{~K}_{2}\right.$ : constant, $\left.\mathrm{K}_{3}=\log \mathrm{K}_{1} \mathrm{~K}_{2}\right)$

In contrast to the calculated relation, equation (4), we found the rate of aggregation is inversely proportional to the logarithm of the particle size in the experiment, shown in Fig. 1. The experimental results indicate that the rate of aggregation does not solely depend on the surface area. It might depend on the concentration of protein and colloidal silica as well. As the rate of aggregation becomes higher, aggregation might become less frequent by the decrease of protein and silica concentrations in the system.

\subsection{Allergen-inactivating effect of colloidal silica}

Before evaluating the allergen-inactivating ability of colloidal silica, we investigated the effects of buffer solutions on the colloidal system. As shown in Table 1, untreated colloidal silica without aluminum on the surface, SNOWTEX XS, was stable in both 0.2-M phosphate buffer and 0.2$\mathrm{M}$ acetic acid buffer at $\mathrm{pH} 5.0, \mathrm{pH} 6.4$, and $\mathrm{pH}$ 7.4. On the other hand, colloidal silica with aluminum bound to the surface, SNOWTEX AK (abbreviated as Al-colloidal silica below), precipitated in 0.2-M phosphate buffer and 0.2-M acetic acid buffer at $\mathrm{pH} 7.4$, but was stable in $0.2-\mathrm{M}$ acetic acid buffer at both $\mathrm{pH} 5.0$ and $\mathrm{pH}$ 6.4. We therefore used the acetic acid buffer at pH 6.4 as the buffer to evaluate the allergen-inactivating effect of colloidal silica using an ELISA. The stability of alumina sol is achieved by the repulsion between positive charges on the surface of the particles, and it is kept at a low $\mathrm{pH}$ because the positive charges on the surface of the alumina sol form an electric double layer with chloride and hydroxyl ion. Therefore, the stability of alumina sol is disturbed at a neutral $\mathrm{pH}$, resulting in precipitation ${ }^{18}$. Al-colloidal silica is thought to precipitate at $\mathrm{pH} 7.0$ in acetic acid buffer because it shows characteristics similar to alumina sol. On the other hand, Al-colloidal silica was precipitated in phosphate buffer at every $\mathrm{pH}$ examined. Al-colloidal silica may form aggregates when its surface charges are neutralized by strong interactions on the surfaces of aluminum cations and hydrogenphosphate ions or dihydrogenphosphate ions in phosphate buffers.

As shown in Fig. 2-1, the ELISA-determined rate of Der $\mathrm{f} 2$ inactivation by colloidal silica was dependent on the size of the colloidal silica particles. Only colloidal silica with a particle size of under $15 \mathrm{~nm}$ had an inactivating effect, and no inactivating effect observed when the particle size was greater than $25 \mathrm{~nm}$. We observed that the smaller the particle size, the greater the inactivating effect. As shown in Fig. 2-1, the minimum concentration required for the almost total inactivation of Der $\mathrm{f} 2$ was $100 \mu \mathrm{g} / \mathrm{mL}$ for $5-\mathrm{nm}$ silica, $150 \mu \mathrm{g} / \mathrm{mL}$ for $10-\mathrm{nm}$ silica, and $300 \mu \mathrm{g} / \mathrm{mL}$ for $15-$ $\mathrm{nm}$ silica. The concentration required for the complete inactivation of Der $\mathrm{f} 2$ was 1.5-fold higher for 10-nm silica and 3-fold higher for 15-nm silica, compared with that required for 5-nm silica. These increases were well correlated with the results for hemoglobin aggregation (3.1), which showed that the aggregation rate increased as the particle size of the colloidal silica decreased. This correlation suggests that the protein binding affinity of the col-

Table 1. Stability of Colloidal Silica in Buffer Solutions.

Colloidal silica was added to each buffer solution to a concentration of $1,000 \mu \mathrm{g} / \mathrm{mL}$, and the solutions were observed at room temperature. SNOWTEX XS: Colloidal silica with $5 \mathrm{~nm}$ particle size; SNOTEX AK: Colloidal silica with $15 \mathrm{~nm}$ particle size and aluminum bound to the surface; (+): precipitated; (-): stable.

\begin{tabular}{lccccccccc}
\hline & \multicolumn{4}{c}{0.2 M Phosphate buffer } & \multicolumn{4}{c}{0.2 M Acetic acid buffer } \\
\cline { 2 - 9 } & $\mathrm{pH}$ & 5.0 & 6.4 & 7.4 & $\mathrm{pH}$ & 5.0 & 6.4 & 7.0 \\
\hline SNOWTEX XS & & - & - & - & & - & - & - \\
SNOWTEX AK & & + & + & + & & - & - & + \\
\hline
\end{tabular}



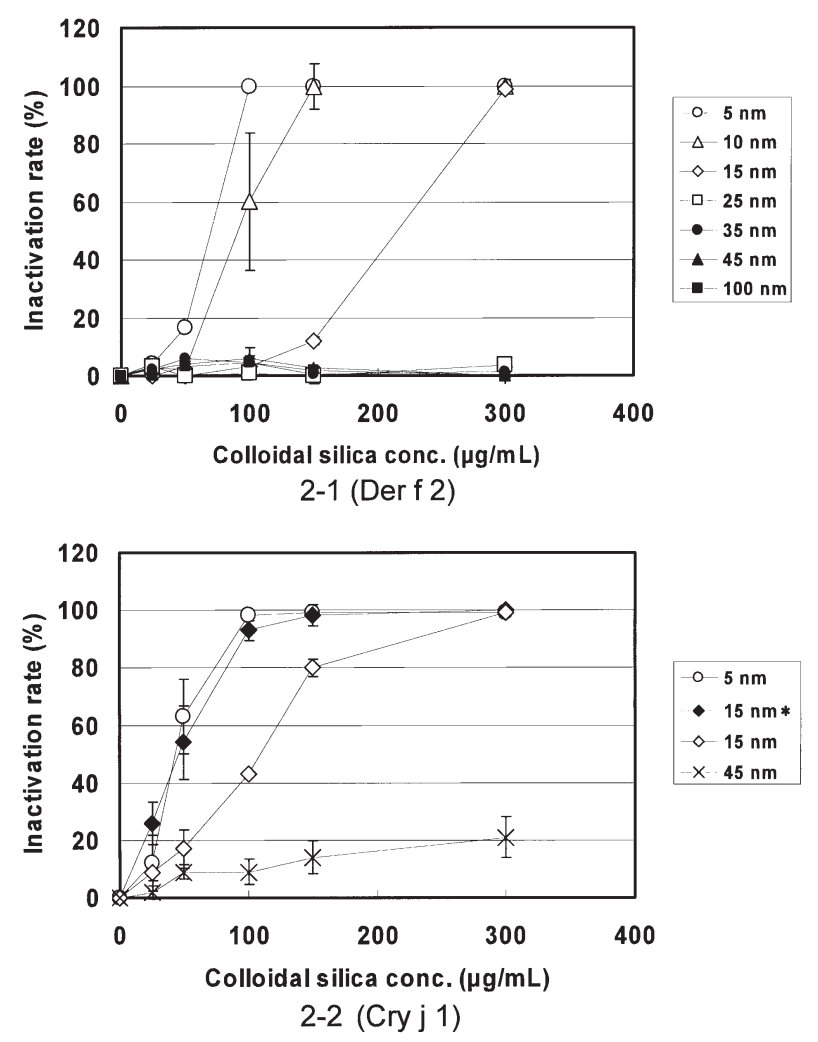

Fig. 2 Allergen Inactivating Effect of Colloidal Silica Measured by ELISA.

Each sample was evaluated by ELISA with wells coated with $150 \mathrm{ng} / \mathrm{mL}$ Der f 2 or Cry j 1. *Colloidal silica with aluminum bound to the surface (Al-colloidal silica).

loidal silica greatly affected allergen inactivation. These relations also agreed with the simplified explanation shown in Table 1. Therefore, the concentration of $25-\mathrm{nm}$ silica required for inactivation may be between $300-400$ $\mu \mathrm{g} / \mathrm{mL}$. Furthermore, as shown in Fig. 2-2, no great differences were found regarding its effect on another allergen, Cry $\mathrm{j} 1$. Even though the present evaluation was limited to Der $\mathrm{f} 2$ and Cry j 1, a large variety of allergens would presumably be inactivated since the protein binding affinity of colloidal silica is non-specific ${ }^{7}$.

As shown in Fig. 2-2, an assessment of the effects of surface treatments on colloidal silica on the inactivation of Cry 1 showed that Al-colloidal silica with a 15-nm particle size yielded almost the same results regarding the concentration-inactivation relation as untreated SNOWTEX XS with a 5-nm particle size. A comparison using particles of the same size $(15 \mathrm{~nm})$ showed that the concentration at which complete inactivation occurred was $150 \mu \mathrm{g} / \mathrm{mL}$ for the Al-colloidal silica and $300 \mu \mathrm{g} / \mathrm{mL}$ for the untreated colloidal silica; thus, the treated colloidal silica was twice as

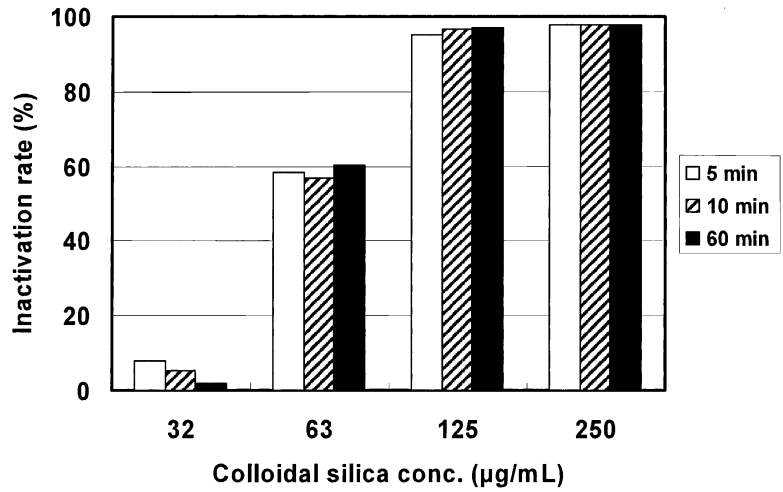

Fig. 3 Allergen Inactivating Effect of Colloidal Silica According to Concentration and Reaction Time. SNOWTEX XS having a particle size of $5 \mathrm{~nm}$ was allowed to react with Cry $\mathrm{j} 1$ coated wells for 5,10 , $60 \mathrm{~min}$.

effective as the untreated colloidal silica. By treating the surfaces of the colloidal silica particles with aluminum, not only silanol groups, but also irreversibly adsorbed aluminum cations are thought to form covalent bonds with one silanol group and to be coordinated by the other silanol group on the colloidal silica surface ${ }^{19)}$. Thus, the surface also exhibits aluminum cation-like properties. Aluminum compounds as well as tannic acid are widely used to modify leather during tanning, since they bind strongly to proteins ${ }^{20)}$. The mechanism of their high affinity has not yet been clarified.

The effects of reaction time on allergen inactivation caused by colloidal silica are shown in Fig. 3 . The allergeninactivating effect of untreated colloidal silica with a particle size of $5 \mathrm{~nm}$ was evaluated against Der $\mathrm{f} 2$ for 5,10 , and $60 \mathrm{~min}$, and the results showed that Der f 2 was similarly inactivated after reaction times of 5 - 60 min at every concentration from $32 \mu \mathrm{g} / \mathrm{mL}$ to $250 \mu \mathrm{g} / \mathrm{mL}$. The difference in the inactivation rates after each of the reaction times for the concentration of $32 \mu \mathrm{g} / \mathrm{mL}$ was thought to be within the range of measurement error. Presumably, the allergens are inactivated in less than 5 min. For allergen inactivation, clearly 1) the particle size of the colloidal silica is critical and should be less than $15 \mathrm{~nm}, 2$ ) surface treatment with aluminum is effective, and 3) only a short time period is required for inactivation.

\subsection{Analysis of the allergen inactivating effect with a $C D$ spectrometer}

Circular dichroism (CD) is a form of spectroscopy based on the differential absorption of left- and right-handed circularly polarized light ${ }^{21}$. A CD spectrometer can be used to determine the structural conformation of proteins. Polylysine adopts an alpha-helix or beta-sheet conformation 


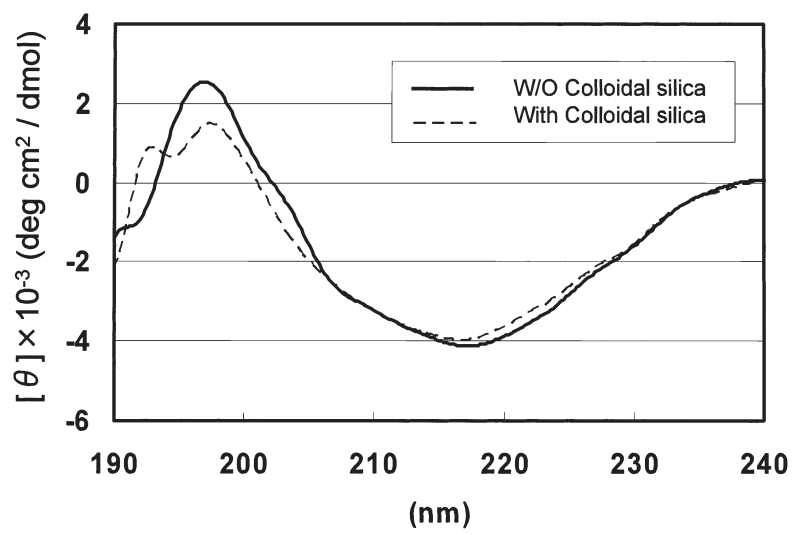

Fig. 4 Circular Dichroism (CD) Spectra of Der f 2 after Reacting with Colloidal Silica.

A $33 \mu \mathrm{g} / \mathrm{mL}$ solution of Der $\mathrm{f} 2$ in $10 \mathrm{mM}$ acetate buffer ( $\mathrm{pH}$ 6.4) with $1 \%$ or without colloidal silica having a particle size of $5 \mathrm{~nm}$ was maintained at $25^{\circ} \mathrm{C}$ for $2 \mathrm{~h}$, and the sample was analyzed by $\mathrm{CD}$ spectrometry.

depending on the $\mathrm{pH}$ and temperature of the aqueous solution containing the compound. The CD spectrum of polylysine in various solutions was analyzed using a CD spectrometer. The presence of an alpha helix conformation was indicated by negative maximum intensities at $222 \mathrm{~nm}$ and $208 \mathrm{~nm}$ and a positive maximum intensity at $191-193 \mathrm{~nm}$ on the CD spectra, while the presence of a beta-sheet conformation was indicated by a negative maximum intensity at $216-218 \mathrm{~nm}$ and a positive intensity at $195-200 \mathrm{~nm}$. Moreover, the amounts of alpha-helix and beta-sheet conformations in each solution were estimated using these intensities ${ }^{22,23)}$. The abilities of surfactants to denature the proteins were also analyzed using the $\mathrm{CD}$ spectra ${ }^{24)}$. The degree to which bovine serum albumin was denatured by each surfactant was indicated by a reduction in the intensity at $220 \mathrm{~nm}$, revealing the presence of an alpha-helix conformation. Kondo et al. used a CD spectrometer to analyze the protein-denaturing effect of colloidal silica ${ }^{7}$. The sample was analyzed using a low buffer concentration to maintain a low salt concentration, since the proteins in aqueous solutions containing colloidal silica form aggregates at high salt concentrations such as the conditions in 2.2. The intensities at $222 \mathrm{~nm}$ and $208 \mathrm{~nm}$, revealing the presence of an alpha-helix conformation, were reduced in solutions containing colloidal silica. These observations indicated that colloidal silica induced a conformational change in the protein. On the other hand, Der $\mathrm{f} 2$ from Dermatophagoides farinae is a sugar protein with a molecular weight of approximately 14,000 Da; Der f 2 is a major allergen that maintains its antigenic activity even after heat treatment. The conformation of Der $\mathrm{f} 2$ was analyzed using multidimensional nuclear magnetic resonance spectroscopy, and a prominent beta-sheet - but no alpha-helix conformation was observed in the small structure ${ }^{15)}$. The beta-sheet is thought to enable the protein to maintain its conformation, preventing heat denaturation.

The conformation of the beta-sheet in Der $\mathrm{f} 2$ was analyzed under conditions similar to those reported by Kondo $^{7}$. As shown in Fig. 4, the two maximum intensities decreased after the addition of colloidal silica. This result indicated a conformational change in Der $\mathrm{f} 2$ and suggested that the colloidal silica was bound to Der f 2 so strongly that a conformational change was induced. Although the mechanism responsible for the allergen-inactivating effect of colloidal silica is unclear, the epitope of the allergen may be covered by the colloidal silica, which exerts a strong protein binding force and blocks the antigen-antibody reactions.

\subsection{Physicochemical characteristics of colloidal silica}

Colloidal silica is known to solidify when it dries ${ }^{8}$, and when the hemoglobin solution with colloidal silica described in 2.2 was dried, it became a rigid agglomeration insoluble in water. It can be thought that colloidal silica would enclose and keep hold of allergens as well as hemoglobin physically. Colloidal silica disperses well in solutions of anionic and nonionic surfactants, and Al-colloidal silica also disperses well in solutions of cationic surfactants. We expect these properties to be convenient for formulating liquid products for allergen inactivation, because surfactants are essential ingredients for formulating liquid products. It is also convenient that colloidal silica will not discolor liquid products with time, as tannic acid does.

\section{CONCLUSION}

The results of this study showed that colloidal silica and Al-colloidal silica have an allergen-inactivating effect. There are no major obstacles to forming liquid products containing colloidal silica from a safety, physical stability, or supply-side stand point. Unlike tannic acid, colloidal silica dose not discolor with time. The development of liquid products containing colloidal silica to inactivate allergens in clothing, floor, bedding, or carpets is expected.

\section{ACKNOWLEDGEMENT}

We are grateful to Nissan Chemical Industries Corporation, Nissei Corporation, ADEKA Corporation, Clariant Corporation, Fuso Chemical Corporation, and Shokubai Chemical Corporation for providing of colloidal silica and significant suggestion. 


\section{References}

1. Yasueda, H. Measurement of environmental allergens. Allergology Tokyo 2, 581-587 (1996).

2. Berge, M.; Munir, A.K.; Dreborg, S. Concentrations of cat (Fel d 1), dog (Can f 1) and mite (Der f 1 and Der p 1) allergens in the clothing and school environment of Swedish schoolchildren with and without pets at home. Pediatric Allergy Immunol. 9, 25-30 (1998).

3. Goodman, N.; Hughes, J.F. Long-range destruction of Der p 1 using experimental and commercially available ionizers. Clin. Exp. Allergy 32, 515-519 (2002).

4. Green, W.F. Abolition of allergens by tannic acid. Lancet 8395, 2 (1984).

5. Ota, A. Plant tannin and leather. Hikaku Kagaku 50, 21-27 (2004).

6. Okonogi, T.; Hattori, Z.; Ogiso, A.; Mitsui, S. Detoxification by persimmon tannin of snake venoms and bacterial toxins. Toxicon. 17, 524-527 (1979).

7. Kondo, A.; Oku, S.; Higashitani, K. Structural changes in protein molecules adsorbed on ultrafine silica particles. J. Colloid Interface Sci. 143, 214-221 (1991).

8. Iler, R.K. The chemistry of silica. John Wiley \& Sons Inc. New York. pp. 364-372 (1979).

9. Ishii, M.; Kakui, T.; Ishiguro, M.; Sato, S. Development of cationic colloidal silica treated with amino-functional silace for ink jet paper. Jpn. TAPPI J. 60, 63-70 (2006).

10. Hahn, G.D.; Possmann, P. Colloidal silicon dioxide as a fining agent for wine. Am. J. Enol. Vitic. 28, 108-112 (1977).

11. Komatsu, M.; Nishida, H. Function and application of colloidal silica for nano-materials. Sen’i Gakkaishi 60, 376-380 (2004).

12. Satoh, G.; Arima, Y.; Nishida, H. Jpn. Pat. 123807 (1988).

13. Yasueda, H.; Yui, Y.; Shimizu, T.; Shida, T. Isolation and partial characterization of the major allergen from Japanese cedar (Cryptomeria japonica) pollen. J. Allergy Clin. Immunol. 77, 77-86 (1983).

14. Ogawa, H.; Higikata, A.; Amano, M.; Kojima, K.; Hukushima, H.; Ishizuka, I.; Kurihara, Y.; Matsumoto, I. Structures and contribution to the antigenicity of oligosaccharides of Japanese cedar (Cryptomeria japonica) pollen allergen Cry j 1: relationship between the structures and antigenic epitopes of plantN-linked complex-type glycans. Glycoconjugate J. 13, 555-566 (1996).

15. Ichikawa, S.; Hatanaka, H.; Yuuki, T.; Iwamoto, N.; Kojima, S.; Nishiyama, C.; Ogura, K.; Okumura, Y.; Inagaki, F. Solution structure of Der $\mathrm{f} 2$, the major mite allergen for atopic diseases. J. Biol. Chem. 273, 356360 (1998).

16. Okuda, T.; Mouri, K.; Aoi, K. Constituents of Geranium thunbergii SIEB. et ZUCC. V. Difference of tannin activities by structural differences. (1). Effects of $\mathrm{pH}$ variations to relative astringency. Yakugaku Zasshi 97, 1267-1272 (1977).

17. Miyazawa, H.; Saitoh, S.; Kumagai, T.; Yamanaka, T.; Yasuda, S.; Tsunetsugu-Yokota, Y.; Inoyue, S.: Sakaguchi, M. Specific IgG to gelatin in children with systemic immediate- and nonimmediate-type reactions to measles, mumps and rubella vaccines. Vaccine 17, 2176-2180 (1999).

18. Watanabe, Y. The synthesis and properties of metal oxide sols. Gypsum \& Lime 211 46-53 (1987).

19. Boehm, H.P. Chemical identification of surface groups. Advances in Catalysis 16, 179-274 (1966).

20. Kubota, M. Tannages with inorganic compounds -mainly on the Iron, and Aluminum tannages. Hikaku Kagaku 20, 1-13 (1974).

21. Yang, J.; Wu, C.; Martinez, H. Methods in Enzymol. (Langone, J.J. ed.). 130, 208-269 (1986).

22. Greenfield, N.; Davidson, B.; Fasman, G.D. The use of computed optical rotatory dispersion curves for the evaluation of protein conformation. Biochem. 6, 16301637 (1967).

23. Greenfield, N.; Fasman, G.D. Computed circular dichroism spectra for the evaluation of protein conformation. Biochem. 8, 4108-4116 (1969).

24. Obu, K.; Jyouna, N.; Miyajima, N.; Mizushima N.; Kashiwa, I. Evaluation of denaturation property of surfactants onto protein as measured by circular dichroism. Yukagaku 29, 866-871 (1980). 